\title{
Epidemiology of Pediatric Medical Emergencies at the Kindu Reference General Hospital (HGRK): State of Affairs and Perspectives
}

\author{
Aime Abdala Kingwengwe ${ }^{1,2,3 *}$, Aubin Kasongo Ndjadi ${ }^{3}$, Patricia Mishika Lukusa4, \\ Paul Makinko Ilunga ${ }^{3}$, Emery Kanyinda Ibeki ${ }^{3}$, Patrick Amuri Kyanga ${ }^{2}$, \\ Taylor Amury Makuburi'2, Delors Mulikita Kitambo², Mick Shongo Pongombo ${ }^{3}$, \\ Gray Kanteng A Wakamb ${ }^{3}$, Nsimbo Assumani ${ }^{3}$, Ernest Kamavuako Nlandu ${ }^{5,6}$, \\ Etienne Shindano Mwamba1,2, Oscar Luboya Numbi ${ }^{3}$, Stanis Wembonyama Okitotsho ${ }^{3}$ \\ ${ }^{1}$ Pediatrics Department, Kindu General Reference Hospital, Kindu, The Democratic Republic of the Congo \\ ${ }^{2}$ Department of Pediatrics, Faculty of Medicine, Kindu University, Kindu, The Democratic Republic of the Congo \\ ${ }^{3}$ Department of Pediatrics, Faculty of Medicine, University of Lubumbashi, Lubumbashi, The Democratic Republic of the Congo \\ ${ }^{4}$ Faculty of Medicine, School of Public Health, University of Lubumbashi, Lubumbashi, The Democratic Republic of the Congo \\ ${ }^{5}$ Department of Basic Sciences, Faculty of Medicine, Kindu University, Kindu, The Democratic Republic of the Congo \\ ${ }^{6}$ Center for Robotics Research, Department of Informatics, King's College London, London, UK \\ Email: *aimeabdala@gmail.com
}

How to cite this paper: A. Abdala Kingwengwe, A. Kasongo Ndjadi, P. Mishika Lukusa, P. Makinko Ilunga, E. Kanyinda Ibeki, P. Amuri Kyanga, T. Amury Makuburi, D. Mulikita Kitambo, M. Shongo Pongombo, G. Kanteng A Wakamb, N. Assumani, E. Kamavuako Nlandu, E. Shindano Mwamba, O. Luboya Numbi, S. Wembonyama Okitotsho (2019) Epidemiology of Pediatric Medical Emergencies at the Kindu Reference General Hospital (HGRK): State of Affairs and Perspectives. Open Access Library Journal, 6: e5715.

https://doi.org/10.4236/oalib.1105715

Received: August 19, 2019

Accepted: September 9, 2019

Published: September 12, 2019

Copyright $\odot 2019$ by author(s) and Open Access Library Inc.

This work is licensed under the Creative Commons Attribution International License (CC BY 4.0).

http://creativecommons.org/licenses/by/4.0/ (c) () Open Access

\begin{abstract}
The management of pediatric medical emergencies is a focus of WHO's strategy to reduce child and adolescent morbidity and mortality worldwide. It requires the synergy of several inputs including infrastructure, equipment and a sufficiently trained staff. The aim of our study was to present the epidemiological aspects of pediatric medical emergencies at Kindu General Reference Hospital in order to facilitate the projection of the actions to be carried out. To do this, we undertook a cross-sectional, descriptive and retrospective study by collecting the data in the pediatric ward of Kindu General Reference Hospital from January 1st to December 31st, 2017 with age, sex, month of admission, emergency sign, diagnostic hypothesis, treatment, length of stay and discharge modality as study's variables in children with an emergency sign (difficulty breathing, convulsion, coma, shock and severe dehydration). After processing data on Excel 2010 and SPSS 23 software, the analysis by descriptive statistical measures shows that the frequency of signs of medical emergency in children is $21.4 \%$ among which $52.3 \%$ are male, over $70 \%$ of children with emergency signs are under the age of five with an average age of 2.1 years, the high frequency of signs of urgency was observed in June, the decreasing order of frequency of various emergency signs is severe dehydration (58.9\%), seizures (24.1\%), difficulty breathing (10.3\%), coma (5.6\%) and
\end{abstract}


the state of shock (1.2\%); Malaria (48.1\%), diarrhea (28.3\%) and meningitis (19.2\%) were common causes of the signs of emergencies, symptomatic treatment for the different signs of urgency was applied in $88.6 \%$ of cases, the duration of hospitalization of children with an emergency sign is less than 4 days in $50 \%$ of cases with an average of $4 \pm 3$ days and mortality among children with a sign emergency in our study is $17.3 \%$. These results highlight the existence of life-threatening medical emergencies in the child in our work environment and require the establishment of a real pediatric emergency unit within the HGRK.

\section{Subject Areas}

Emergency \& Critical Care, Nursing, Public Health

\section{Keywords}

Emergency, Child, Epidemiology, Monitor, Resuscitation, Kindu

\section{Introduction}

The definition of an emergency in pediatric practice has a varied term. For this work, the pediatric emergency is defined as a state threatening the child's life in a \pm short time and requiring a fast and adequate management [1] [2]. It is necessary to distinguish medical emergencies, which are the subject of our study and whose care is limited to medical means, to surgical emergencies whose care extends to surgical means. Also, among the medical emergencies, one distinguishes the true urgencies of emergencies felt. These are often subjective because they are classified as such by parents for various reasons [3]. Because of the fragility of the child, the boundaries between benign and severe morbid conditions are less clear, especially in children under 30 months, where a common ailment can quickly become complicated [9].

Many child deaths in hospitals occur within 24 hours of admission, whereas they could be avoided if very sick children are identified shortly after arrival and treatment is initiated immediately [1] [4]. These deaths are caused by conditions that are immediately life-threatening. These conditions are observed most often in developing countries, including the Democratic Republic of Congo (DRC), and are either an airway obstruction and other respiratory disorders, a shock, a serious alteration of the function of the patient. central nervous system (coma or convulsions) and severe dehydration [1].

Pediatric medical emergencies represent a real public health problem around the world with an estimated prevalence of between $4.5 \%$ and $50 \%$ depending on the region. The dramatic nature that accompanies them reinforces the interest of their knowledge and care [5] [6] [7] [8]. The prevalence is higher in areas where there is no careful sorting that can dissociate emergencies from true emergencies but also where infant-juvenile morbidity is still high [3]. The importance of pe- 
diatric medical emergencies in Africa is due to several factors that are most often entangled: the economic precariousness of populations, the late use of care and the inadequate management of pre-hospital medical centers.

WHO has developed Guidelines for Child Triage, Assessment and Emergency Treatment (TEAT) to reduce childhood morbidity and mortality related to pediatric emergencies. These guidelines are inspired by those used in the West (PALS). They have been developed in Malawi and field tested in several countries including Angola, Brazil, Cambodia, Indonesia, Kenya and Niger.

In the DRC, in general, and in Kindu (Maniema Province) in particular, pediatric medical emergencies are common in hospitals. WHO's guidelines are less popular and almost not enforced. In addition, we find a paucity of literature on pediatric emergencies in our clinician work environment.

The general objective of the study was to reduce infant and child morbidity and mortality in emergencies in the DRC in general and in Kindu, Maniema Province, in particular through knowledge of the local medical environment. In particular, the present work aimed to present the epidemiological aspects of pediatric medical emergencies to the Kindu Reference General Hospital with a view to facilitating the projection of the actions to be carried out.

\section{Methodology}

The HGRK is the provincial health facility of reference in Maniema (DRC) and is located in the capital of this province of eastern DRC. It does not yet have a pediatric emergency unit within it.

This was a cross-sectional, descriptive and retrospective study of the data collected in the pediatric ward of the Kindu Reference General Hospital from 01 January to 31 December 2017.

From the patient files, we selected the cases that presented one of the true emergency signs according to the WHO TETU scale. This is respiratory difficulty, convulsion, coma, shock and severe dehydration. Newborns are voluntarily excluded from this study as they participate in another neonatal emergency study and cover the same time period.

The variables selected for our study are: age, sex, month of admission, urgency sign, diagnostic hypothesis, treatment, length of hospital stay and discharge modality.

The data was processed using Excel 2010 and SPSS 23 software. The analysis used descriptive statistical measures such as percentage and average.

To carry out this study, we obtained the approval of the Department of Pediatrics and the Faculty of Medicine of Kindu University (UNIKI) and the authorization of the HGRK Directorate for the collection of data. Patient anonymity was rigorously respected throughout the harvesting process.

\section{Results (Tables 1-4 and Figure 1)}

We collected a total of 428 cases of children admitted to the HGRK who pre- 
sented an emergency sign before or during their admission to the Pediatric Department during the year 2017. This represents a frequency of $21.4 \%(428 / 2000)$.

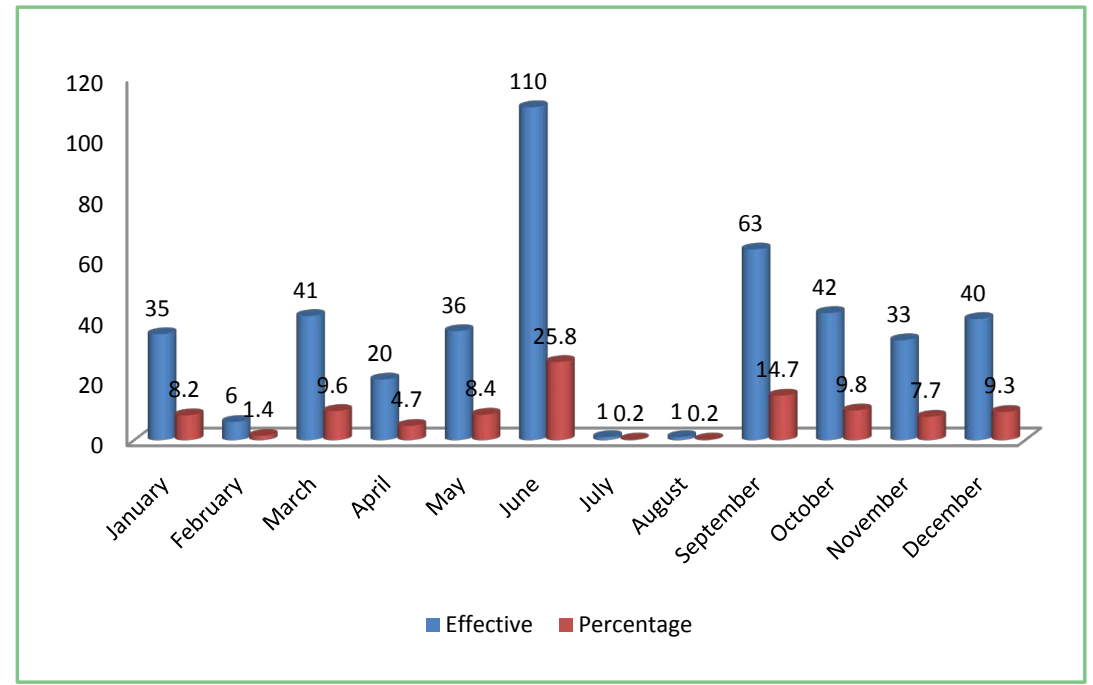

Figure 1. Distribution of cases by month of admission.

Table 1. Age groups and sex.

\begin{tabular}{ccc}
\hline Variables & Effective $(\mathbf{n}=\mathbf{4 2 8})$ & Percentage \\
\hline Age groups & 112 & 26.2 \\
Infant (1 to 23 months) & 198 & 46.3 \\
Small child (24 to 59 months) & 60 & 14.0 \\
Child (5 to 12 years old) & 47 & 11.0 \\
Great child (13 to 14 years old) & 11 & 2.6 \\
Teenager (15 to 18 years old) & & \\
Sex & 224 & 52.3 \\
Male & 204 & 47.7 \\
Female & & \\
\hline
\end{tabular}

Table 2. Emergency signs.

\begin{tabular}{ccc}
\hline Signs & Frequency & Percentage \\
\hline Severe dehydration & 252 & 58.9 \\
Convulsion & 103 & 24.1 \\
Respiratory difficulty & 44 & 10.3 \\
Coma & 24 & 5.6 \\
Shock & 5 & 1.2 \\
Total & $\mathbf{4 2 8}$ & 100.0 \\
\hline
\end{tabular}


Table 3. Diagnostic assumptions associated with emergency signs.

\begin{tabular}{ccc}
\hline Assumptions & Effective $(\mathbf{n}=\mathbf{4 2 8})$ & Percentage \\
\hline Malaria & 206 & 48.1 \\
Digestive diarrheal infection & 121 & 28.3 \\
Meningitis & 82 & 19.2 \\
Respiratory infection & 27 & 6.3 \\
Septicemia & 23 & 5.4 \\
Other & 7 & 1.6 \\
\hline
\end{tabular}

Table 4. Therapeutic and evolutionary data.

\begin{tabular}{ccc}
\hline Variables & Effective $(\mathbf{n}=\mathbf{4 2 8})$ & Percentage \\
\hline Symptomatic treatment & 379 & 88.6 \\
Applied & 49 & 11.4 \\
Not applied & & \\
Duration of hospitalization & 215 & 50.2 \\
Less than 4 days & 175 & 40.9 \\
4 to 7 days & 38 & 8.9 \\
More than 7 days & & 78.3 \\
Exit modality & 335 & 17.1 \\
Healing & 73 & 4.7 \\
Deaths & 20 & \\
SCAM & & \\
\hline
\end{tabular}

$\mathrm{SCAM}=$ Sortie Contre Avis Médical $=$ Out Against Medical Notice.

Children under 5 represent more than $70 \%$ of all registered emergencies. The average age of all cases is 2.1 years. The male sex is represented with $52.3 \%$ or a sex ratio of 1.1 for the male.

June is the month in which $25.8 \%$ of children with an emergency sign were registered.

Severe dehydration is the sign of urgency observed in $58.9 \%$ of cases followed by convulsions (24.1\%), respiratory difficulty (10.3\%), coma (5.6\%) and shock $(1.2 \%)$.

Malaria, digestive tract infection with diarrhea and meningitis are the pathologies mentioned in most children who presented the emergency signs with respective proportions of $48.1 \%, 28.3 \%$ and $19.2 \%$. The other hypotheses evoked were respiratory infection (6.3\%) and sepsis (5.4\%).

Symptomatic treatment for the various signs of urgency was applied in $88.6 \%$ of cases and $11.4 \%$ of cases did not receive specific symptomatic treatment.

Fifty percent (50\%) of cases stayed less than 4 days in hospital. The average stay of registered cases is $4 \pm 3$ days. Hospital mortality among children with an emergency sign is $17.3 \%$. 


\section{Discussion}

This study has a major limitation in that it did not take place in a conventional unit devoted to pediatric emergencies due to its non-existence.

The frequency of medical emergency' signs in children in our study environment is $21.4 \%$ of which $52.3 \%$ are male. The frequency of emergencies observed in our study is close to those observed by Sagnes [9] in France (20.5\%), Gravel et al. [10] in Canada (30\%) but higher than those recorded in other hospitals in France by Grimprel and Bégué [3], which ranged between $8.5 \%$ and $14 \%$. Our observation is far inferior to those of the African studies that we found. These are the studies of Atanda et al. in Congo-Brazzaville [6], Dan V et al. in Benin [5], Fatou et al. in Senegal [11] and Diarra in Mali [12] who found respectively $70 \%, 60 \%, 57.2 \%$ and $52.9 \%$ of cases among pediatric consultations in their respective study environments. This high frequency of pediatric emergencies in other African studies is justified by the difference in case definition. The sister studies did not dissociate real emergencies from those felt. It is therefore imperative that the WHO sorting scale be disseminated within our continent's health care structures in order to reduce the overestimation of pediatric emergencies.

Several studies of pediatric emergencies report high male to female representation [4] [5] [6] [11]-[20]. The predominance of the male sex suggests the hypothesis of greater susceptibility of the male sex to the female sex in the lower age of life in the face of morbid phenomena.

In our series, more than $70 \%$ of children with emergency signs are under five with an average age of 2.1 years. Our observation corroborates with those of Ndukwu [4], Fatou [11], Dan [5] and Atanda [6]. This result is explained by the vulnerability of this age group and its susceptibility to several pathologies that weaken its immune status.

The high frequency of signs of urgency was observed in June in our series with $25.8 \%$ of all cases. We have not found in the literature a recent study that shows the monthly frequency of pediatric emergencies. However, Dan et al. [5] observed a peak of cases in pediatric emergencies in January at the National Hospital and University Center of Cotonou from 1 January to 31 December 1988. The study of one year will allow us to justify the finding on the monthly frequency of emergencies pediatric.

The decreasing order of frequency of various emergency signs in our series is made of severe dehydration (58.9\%), seizures (24.1\%), respiratory difficulty (10.3\%) coma (5.6\%) and shock (1.2\%). Apart from the fact that severe dehydration comes first in our series, the order of frequency of other emergency signs is similar to other studies consulted. Also, in the studies of references appear certain signs which were not retained in ours. For Diarra [9] for example, the order is made of fever (25.5\%), convulsions (24.5\%), pallor (18.6\%), difficulty breathing (8.9\%), coma (8.6\%) and dehydration (5\%). In the study of Fatou et al. [11], it appears an order made of difficulty breathing (30.2\%), digestive disorders 
(28.7\%), fever (20.1\%) and neurological disorders (12.9\%). This result may suggest a poor assessment of dehydration in our environment leading to its overestimation. However, the importance of dehydration in its entirety, convulsions and difficulty breathing remains relevant.

Malaria (48.1\%), diarrhea (28.3\%), meningitis (19.2\%), respiratory infections and sepsis were the diagnostic assumptions frequently associated with signs of emergencies. This observation is identical to that of Coulibaly et al. [20] who found that the pathologies associated with pediatric emergencies were dominated by severe malaria for $32.72 \%$, severe diarrhea dehydration with $11.26 \%$ followed by meningitis in $9.42 \%$ of cases. Ndukwu et al. [4] identified four pathologies with malaria at the top (19.5\%) followed by diarrhea $(17.7 \%)$, acute respiratory infections (14.2\%) and sepsis (7.5\%). These data suggest pediatric emergencies offer a wide range of etiologies but clinicians should direct their first-line investigations to infectious pathologies that, on the clinical plane of expression, can be associated with any sign of urgency in the child.

The symptomatic treatment for the different signs of urgency was applied in $88.6 \%$ of cases. Our results are similar to those of Diarra [9] who in his series found that emergency treatment was given to $79.8 \%$ of patients against $20.2 \%$ who had not received it. It remains now that a future study looks at the means used in the implementation of emergency treatment in our environment.

The duration of hospitalization of children who presented an emergency sign in our study is less than 4 days in $50 \%$ of cases with an average of 4 days \pm 3 . Our results are contrary to those of Diarra [9] who found that $72.2 \%$ of cases stayed 4 days or more in hospital. However, other pediatric emergency studies focused on the children's stay in the emergency unit. Nevertheless, we can say that the establishment of a real unit of pediatric emergencies at the HGRK can help to significantly reduce sometimes inappropriate hospitalizations among children.

Mortality among children with an emergency sign in our study is $17.3 \%$. This mortality rate is not far from the observations made by Bains et al. [13] in India (16.3\%), Diarra [12] in Mali (15\%) and Ndukwu et al. [4] in Nigeria (12.6\%). Our observation is superior to those of Dan [5] and Atanda [6] who respectively found mortality rates of $10.8 \%$ and $3.9 \%$.

\section{Prospectives}

From this state of affairs described by our work, we believe that improving the management of pediatric medical emergencies at the HGRK requires:

- Development and equipment of an emergency room at the Pediatrics Department,

- The training of the medical staff on the directives of the triage, assessment and treatment of emergencies in the child,

- The training focused on the management of common pathologies and frequently at the origin of emergency situations in children,

- Pursuing publications on pediatric emergencies in the region. 


\section{Conclusion}

Pediatric medical emergencies are common in the HGRK and certainly in other health facilities in the City of Kindu and even in the Province of Maniema. An extension of the WHO guidelines on triage, assessment and emergency treatment coupled with the planning and equipment of spaces specifically for emergency care is essential to hope to reduce child morbi-mortality.

\section{Conflicts of Interest}

The authors declare no conflicts of interest regarding the publication of this paper.

\section{References}

[1] OMS, Triage, évaluation et traitement d'urgence (TETU) (2010) Manuel du participant-Guide de l'animateur, Organisation mondiale de la Santé.

[2] Hazoume, F.A., Pohlmann, A. and Baba Moussa, A. (1977) Urgences Pédiatriques à Cotonou. Médecine d Afrique Noire, 16, 149-153.

[3] Grimprel, G. and Bégué, P. (2013) Les urgences en pédiatrie dans les hôpitaux d'enfants. Bulletin de L'Académie Nationale de Médecine, 197, 1127-1141. https://doi.org/10.1016/S0001-4079(19)31481-5

[4] Ndukwu, C.I. and Onah, S.K. (2015) Pattern and Outcome of Postneonatal Pediatric Emergencies in Nnamdi Azikiwe University Teaching Hospital Nnewi, South East Nigeria. Nigerian Journal of Clinical Practice, 18, 348-353. https://doi.org/10.4103/1119-3077.153246

[5] Dan, V., Hazoume, F.A., Ayivi, B. and Koumakpai, S. (1991) Prise en charge des urgences dunourrisson et de l'enfant: Aspectsactuels et perspectives d'avenir au Centre National Hospitalier de Cotonou. Médecine d Afrique Noire, 38, 752-759.

[6] Atanda, H.L., Porte, J., Bon, J.C., Force-Barge, P. and Rodier, J. (1994) Place des urgences médicales pédiatriquesdans un service médical à Pointe-Noire. Médecine d' Afrique Noire, 41, 17-20.

[7] Hue, V., Walter-Nicolet, E., Martinot, A. and Commission des urgencies (2004) Implication des Pédiatres dans l'accueil des urgences: Enquête "Un jour donné" auprès des centres hospitaliers et despédiatres libéraux de la région Nord-Pas de Calais. Archives de Pédiatrie, 11, 1191-1196. https://doi.org/10.1016/j.arcped.2004.04.021

[8] Devictor, D. (1994) Urgences en Pédiatrie: Données chiffrées. In: Journées parisiennes depédiatrie, Flammarion. Médecines-Sciences, Paris, 381-386.

[9] Sagnes-Raffy, C., Claudet, I., Grouteau, E., Fries, F. and Ducassé, J.L. (2001) Epidémiologie des urgences de l'enfant de moins de 2 ans.

[10] Gravel, J., Gouin, S., Goldman, R.D., Osmond, M.H., Fitzpatrick, E., Boutis, K., et al. (2012) The Canadian Triage and Acuity Scale for Children: A Prospective Multicenter Evaluation. Annals of Emergency Medicine, 60, 71-77. https://doi.org/10.1016/j.annemergmed.2011.12.004

[11] Fatou, L.Y., Keita, Y., Niang, B., et al. (2016) Profil épidémiologique des consultants admis aux urgences médicales pédiatriques du Centre Hospitalier National de Pikine. RAMReS Sciences de la Santé, 4, 4-10. http://publication.lecames.org/index.php/sante/article/view/927/632

[12] Diarra, N.C. (2009) Bilan d'activité d'une annéeau service des urgencespédiatriques 
du CHU Gabriel Touré. Master Thesis, Faculté de Médecine, de Pharmacie et d'Odontostomatologie.

http://www.keneya.net/fmpos/theses/2010/med/pdf/10M95.pdf

[13] Bains, H.S. and Soni, R.K. (2012) A Simple Clinical Score TOPRS to Predict Outcome in Pediatric Emergency Department in a Teaching Hospital in India. Iranian Journal of Pediatrics, 22, 97-101.

[14] Ibrahim, Y.T. (2013) Les urgences pédiatriques au Centre de santé de la Commune V. Thèse Méd., Mali.

[15] Abdou, R.O., et al. (2002) Les urgences pédiatriques au Centre Hospitalier de Libreville. Médecine d' Afrique Noire, 49, 475-480.

[16] Diane, N.E. (2007) Prise en charge des urgences pédiatriques: Contraintes, coûts et prognostic. Thèse Med., Dakar, No. 126.

[17] Ibeziako, S.N. and Ibekwe, R.C. (2002) Pattern and Outcome of Admissions in the Children's Emergency Room of the University of Nigeria Teaching Hospital, Enugu. Nigerian Journal of Paediatrics, 29, 103-107. https://doi.org/10.4314/njp.v29i4.12018

[18] Adeboye, M.A., Ojuawo, A., Ernest, S.K., Fadeyi, A. and Salisu, O.T. (2010) Mortality Pattern within Twenty-Four Hours of Emergency Paediatric Admission in a Resource-Poor Nation Health Facility. West African Journal of Medicine, 29, 249-252. https://doi.org/10.4314/wajm.v29i4.68245

[19] Weir, L.M., Hao, Y., Owens, P.L. and Washington, R. (2013) Overview of Children in the Emergency Department, 2010. Healthcare Cost and Utilization Project. Agency for Healthcare Research and Quality, Rockville, Statistical Brief, 157. http://www.hcup-us.ahrq.gov/reports/statbriefs/sb157.pdf

[20] Coulibaly, B. (2006) Urgences médicales dans le service de pédiatrie du CHU Gabriel Touré. Thèse Med., Bamako, No. 265.

http://www.keneya.net/fmpos/theses/2006/med/pdf/06M265.pdf 